\title{
The Deployment of Scaffolding as a Strategy to Enhance Students’ Reading Competence: A Case of Indonesian EFL Teachers
}

\author{
Lanjar Utami ${ }^{1}$, Joko Nurkamto ${ }^{2}$, Nunuk Suryani ${ }^{2}$, Gunarhadi ${ }^{2}$ \\ ${ }^{1}$ Education Science Department, Graduate Program, Universitas Sebelas Maret \\ Surakarta, Jl. Ir. Sutami No. 36A, Jebres, Solo, Central Java, Indonesia \\ ${ }^{2}$ Education and Teacher Training Faculty, Universitas Sebelas Maret Surakarta, Jl. Ir. \\ Sutami No. 36A, Jebres, Solo, Central Java, Indonesia
}

\begin{abstract}
Scaffolding is a type of instructional strategy in socio-cognitive perspective. It can be used to support and foster students' reading competence in reading comprehension lesson. However, there were not many teachers deploying it in their classroom practices. This research explored the types of scaffolding the teachers deployed in the teaching of reading and the enactment of using those types to enhance students' reading competence. To investigate these issues, document analysis, in-depth interviews and participant classroom observation, were used as data collection methods in this explorative case study. The data were analyzed using interactive model technique. Five English teachers participated in this study. The research findings showed that the teachers utilized scaffolding in the forms of reading strategies and instructional media. Those types of scaffolding were implemented in five steps of scientific approach. It is recommended that the teachers understand the concept and use scaffolding in the form of different types of strategy to foster students' reading competence.
\end{abstract}

Keywords: scaffoldings; socio-cognitive perspective; strategy; reading comprehension

\section{INTRODUCTION}

Reading competence has become a global issue. It determines the position of a country compared to other countries. The better a country can achieve a position, the better human resources the country shows [1]. Researches on reading competence through the Program for International Student Assessment (PISA) showed that the result of Indonesian students' reading competence was low. It was in the rank 57 of 65 surveyed countries (2009), rank 64 of 65 surveyed countries (2012), and rank 69 of 76 surveyed countries (2015). The level of reading competence in each term was far left behind the average scores of all surveyed countries. Indonesian students' reading 
competence was worse than that of neighboring countries, such as Thailand, Malaysia, Vietnam, and Singapore [1].

In national and regional scopes, reading competence is designated as a determiner for students' success in national examination in Senior High Schools (SMA), including in "Madrasah Aliyah" (MA) in Indonesia. The material of English national examination emphasizes on reading competence. Based on the result of English national examination of SMA/MA in 2016, it is seen that the average score of national examination is still not satisfying. The data reported from Ministry of Education and Culture showed that the average score of English national examination were 51.18 for science and 46.74 for social science program [2]. The average scores were still under the minimum requirement standard declared by the government.

Responding to the crisis of students' reading competence, some researchers offer effective ways to facilitate students' reading comprehension. One of the effective techniques the teachers can deploy is scaffolding. Scaffolding is an important teaching strategy that closely derived from Vygotsky's socio-cognitive theory and his concept of the Zone of Proximal Development (ZPD) [3]. Scaffolding refers to the assistance offered by others to be able to achieve more than someone would be able to achieve alone in the ZPD. It provides individualized support based on the learners' ZPD [3]. According to Vygotsky (1978), with the guidance and support of an expert, students are able to perform tasks and activities that are slightly beyond their own independent knowledge and capability [4,5]. As they become more knowledgeable and experienced with the task and activities, the support or assistance is withdrawn little by little, and then the students will internalize the new knowledge and experiences they have acquired, which results in learning.

Being practiced in reading activity, scaffolding is relevant to the application of reading strategies. Learner strategies allow the learners to take responsibility for their own language learning. They posit that these learning strategies help them to solve learning problems, and as a result, students may become autonomous language learners. When the reading strategies are outlined by good readers, teachers can use them to motivate poor readers thereby helping them learn more effectively. However, there are not many teachers deploying scaffolding as a strategy to enhance students' reading text comprehension. This study, therefore, explored primarily upon the types of scaffolding the teachers deployed and the enactment of using those types in the teaching of reading. 


\section{RESEARCH METHOD}

This research employed a case study exploring primarily upon the types of the scaffolding teachers deployed in the teaching of reading and the enactment of using those types to enhance students' reading competence.

The research was held at MA Central Java, Indonesia. The participants of the case study were five senior English teachers from Central Java. They were two male and five female senior English teachers, for having specific qualifications, namely: (1) they have at least four years formal education at a university level (strata 1), (2) they have been teaching at least for five years, (3) they have been certified as professional teachers, (4) they are active members and committee of English Teacher Association (ETA), and (5) they have received certificate for 2013 curriculum workshop.

The data sources in this study consisted of informants, events, and artifacts. In this study, the informants were senior English teachers from different schools, who were considered to have enough knowledge, beliefs, and practice on the use of scaffolding to foster students' reading competence. They were also considered to be able to give the information in details. The events referred to the process of teaching reading done by the teachers deploying scaffolding to teach reading comprehension in the classrooms. Artifacts constituted the documents the teachers made use of in teaching, such as teaching lesson plan, teaching materials, and instructional media.

The process of collecting data was first started by analyzing the teachers' documents in teaching reading comprehension comprising of teaching lesson plan, teaching material, and instructional media. Then, the participants were interviewed orally and individually based on the interview protocol. The whole interview guide was first showed to the participants to read since by knowing the questions in advance the participants got a good understanding on the points of question so that they could give information needed more accurately. Both document analysis and in-depth-interviews were intended to identify the types of scaffolding teachers deployed in the teaching of reading in the classroom. Next, classroom observation was conducted in five different reading classrooms. It was to observe the enactment of the use of scaffolding types the teachers deployed to enhance students' text comprehension. The researcher did observation, identification, analysis, and evaluation of what she watched in the class based on the intended points prepared in observation sheet. She jotted down how the process of teaching was conducted. The researchers also took photograph and recorded the teachers' practice in the classroom. Finally, focus group discussion (FGD) was performed together with all participants. The researchers re-interviewed some of the participants to confirm some key information to avoid the inaccuracy of data.

To guarantee the validity of the collected data, data source and method, triangulation was implemented to make the final results more reliable [6]. The process of triangulation took several and constant revisions in order to end with meaningful and accurate information for this research $[7,8]$. An interactive model technique was applied 
to analyze the collected data. The component of data analysis of the interactive model includes for stages, namely (1) collecting the data, (2) reducing the data, (3) displaying the data, and (4) drawing conclusion $[7,8]$.

\section{THE FINDINGS AND DISCUSSION}

The research findings and discussion referred to the research questions. They focused on the types of scaffolding teachers deployed in the teaching of reading and the enactment of using those types of scaffolding to enhance students' text comprehension. They were described in the following sections.

\section{The Types of Scaffolding Teachers Deployed in the Teaching of Reading}

Based on the result of document analysis, it was found that the teachers planned to deploy scaffolding in the teaching of reading. It can be seen from their lesson plans, in the aspects of teaching objectives, teaching procedures, teaching materials, and teaching media. However, when they were asked about scaffolding, they answered that they did not know what scaffolding was. It seemed that they were not aware of having planned to deploy some types of scaffolding in their lesson plans. After the researcher explained the concept of scaffolding and the types of it in "Bahasa Indonesia" they spontaneously answered in a choir that they had been deploying some types of scaffoldings in teaching reading. Then, they said that scaffolding is very beneficial as a bridge to connect the teacher and students to attain the objectives.

Each aspect of lesson plan contains the type of scaffolding deployed in the teaching. The aspect of teaching objectives reflects teaching strategy by guiding students to focus on the objective they would attain. It will help students limit and direct their activities orienting to the objectives of the lesson. The aspect of teaching procedure reflects the teaching steps to be followed in achieving the objectives. The teaching steps followed the scientific approach (SA) consisting of observing, questioning, experimenting, associating, and communicating. They could be classified into three phases, namely pre reading, while reading and post reading. The aspect of teaching materials showed the model of text/genre that would be taught to students. The model helped the students to understand the kinds of text/genre, language features, and text structure. They facilitate students' text understanding. The aspect of teaching media indicated the kinds of media used to help students understanding the texts. The media took the forms of picture and video. They could increase students' learning motivation and enhance text comprehension.

Viewed from socio-cognitive perspective, scaffolding the teachers deployed in the teaching of reading took in the forms of different strategies and instructional media. Strategy refers to the plan that students are able to implement when they are reading [9]. 
When comprehension is difficult to achieve, students are able to implement a plan or strategy to restore their own comprehension. Through strategies modeling and practice, the teachers provide scaffolding of reading and then when students are able to enhance their competence, the teachers gradually removed the supports as students are able to monitor their own comprehension. Through the scaffolding in the form of strategies, the students' comprehension of text remains the primary focus. In addition, the teacher's goal is to help students become independent readers.

The instructional media the teachers deployed in teaching reading was visual media in the form of pictures. They referred to non-photographic and two dimensional materials which is utilized by the teachers to convey messages to the students. This kind of material basically not only includes pictures but also drawings, charts, and graphs. The teachers only used pictures because they are easy to find and practical. They like using pictures because they can help students learn better and get several benefits, namely: (1) the use of pictures enables the students to learn and memorize the materials easily, (2) the use of pictures can improve the students' interest and motivation, (3) the use of pictures can improve the students' participation, (4) the use of picture can improve the students' self-confidence, (5) the use of picture can improve the students' personal relationship, and (6) the use of picture can improve the students' attitude and behaviour.

The teachers' reason for deploying the pictures is that that they offer several benefits to the teaching of reading comprehension [10]. They can help students understand various aspects of foreign language. They have motivated the students and made the subjects they are dealing clearer. They also can illustrate the general idea and forms of an object or action which are particular to a culture. Accordingly, the teachers are advised to consider the following principle when using those media. First, the picture is easy to prepare. It is very easy for the teacher to prepare a picture as teaching media. It only takes a little time to prepare the picture but teacher can use it many times with different classes and even different topics. Once teacher has built up a picture library it is usually not difficult to prepare the activities suggested in the book. Second, picture is easy to organize. It is easy to organize in the classroom. Activity using a picture does not require much organizational time and energy. Third, picture is interesting. Picture is usually interesting to the students and the teachers. In this way, the teacher should be wise to consider the activity which is worth doing by using pictures. Fourth, picture is meaningful and authentic. The language and the way the teacher wants the students to use the picture is authentic and intrinsic to the activity. Fifth, picture provides sufficient amount of language. The activity by using picture will give rise to a sufficient amount of language in order to justify its inclusion in the language lesson.

Besides that, video can take the teachers' position as the facilitator. The use of video can (1) help students in retaining the subject content learnt, (2) help to contextualize learning, (3) stimulate the cognitive aspect of learning in ESL classrooms, (4) engage ways to present ideas and concepts that will increase the interest and motivation of 
students to participate in a given topic; (5) increase the ability of students to view media for more than just entertainment value alone (5) serve as a strategy to create an experiential learning environment where students feel emerged in the events or situations they are learning about [11,12].Based on the explanation, it means that the teachers have planned scaffolding in the form of reading strategies and instructional media to enhance students’ reading competence.

\section{The Enactment of using the types of Scaffolding in the Teaching of Reading}

The five senior English teachers joining this study enacted the use of scaffolding types in the teaching of reading. The five enactments can be classified into two practices of teaching reading focusing on two different topics, namely the fairy tale entitled "Cinderella" (first grade) and news items entitled "Celeb of the year" (third grade). The summary of those practices can be seen at table 1 and 2 .

\section{TABLE I. THE ENACTMENT OF SCAFFOLDING TYPES USED IN TEACHING NARRATIVE TEXT}

\begin{tabular}{|l|l|}
\hline Phases & Narrative Text Teaching \\
\hline Observing & $\begin{array}{l}\text { a. The teacher showed and asked students to observe some pictures about } \\
\text { fairy tales on the slides. } \\
\text { b. The teacher asked students to work in pairs discussing the pictures. }\end{array}$ \\
\hline Euestioning & $\begin{array}{l}\text { a. The teacher asked questions related to the pictures showed on the slides. } \\
\text { b. The teacher explained the students explaining that they would study a } \\
\text { fairy tale entitled Cinderella. }\end{array}$ \\
\hline Associating & $\begin{array}{l}\text { a. The teacher asked the students to read the text in the distributed sheet } \\
\text { b. The teacher asked the students to find out what words were difficult for } \\
\text { them }\end{array}$ \\
& $\begin{array}{l}\text { c. The teacher asked and explained the meaning of new words to whole } \\
\text { class. }\end{array}$ \\
& $\begin{array}{l}\text { e. The teacher explained the social function, generic structure and linguistics } \\
\text { ftudents. }\end{array}$ \\
\hline Communicating & $\begin{array}{l}\text { The teacher asked students to do a list of questions following the text. } \\
\text { directly }\end{array}$ \\
\hline & $\begin{array}{l}\text { a. The teacher reviewed the text content and provided a question and answer } \\
\text { session. } \\
\text { b. The teacher gave homework to students. }\end{array}$ \\
\hline
\end{tabular}


TABLE II. THE ENACTMENT OF SCAFFOLDING TYPES USED IN TEACHING NEWS ITEMS TEXT

\begin{tabular}{|c|c|}
\hline Phases & News Items Text Teaching \\
\hline Observing & $\begin{array}{l}\text { a. The teacher showed and asked students to observe a video played and } \\
\text { showed on the screen. } \\
\text { b. The teacher asked students to work in pairs discussing the content of } \\
\text { video. }\end{array}$ \\
\hline Questioning & $\begin{array}{l}\text { a. The teacher asked questions related to the video showed on the slides. } \\
\text { b. The teacher explained to the students that they would study a news item } \\
\text { text. }\end{array}$ \\
\hline Experimenting & $\begin{array}{l}\text { a. The teacher asked the students to read the text in the distributed sheet } \\
\text { b. The teacher asked the students what words were difficult for them } \\
\text { c. The teacher asked and explained the meaning of new words to whole } \\
\text { class. } \\
\text { d. The teacher explained the social function, generic structure and } \\
\text { linguistics feature of the text. } \\
\text { e. The teacher provided opportunity for asking and answering session for } \\
\text { students. }\end{array}$ \\
\hline Associating & $\begin{array}{l}\text { a. The teacher asked students to do a list of questions following the text. } \\
\text { b. The teacher checked the students' answer one by one and corrected it } \\
\text { directly }\end{array}$ \\
\hline Communicating & $\begin{array}{l}\text { a. The teacher reviewed the text content and provided a question and } \\
\text { answer session. } \\
\text { b. The teacher gave homework to students. }\end{array}$ \\
\hline
\end{tabular}

The findings showed that what the teachers practiced in the classroom was different from what they planned in the teaching scenario. It can be seen from the followings. Firstly, the teacher planned teaching objectives but in fact $80 \%$ teachers forgot to state the objectives in the classrooms. They taught directly telling the topic instead of guiding them to the teaching objectives. It means that they have left one strategy to activate students' background knowledge in the pre reading activities. Secondly, the phases of teaching procedure of SA seemed to have no function as scaffolding explicitly since they remained mentioning the phases into three phases of reading activities, namely pre reading, while reading, and post reading activity. Thirdly, the use of instructional media in the forms of picture and video seemed not to function well and for the sake of increasing students' interest. Finally, strategies and instructional media could not be implemented optimally in the teaching of reading.

Based on the result of classroom observation, it can be said that the teachers deployed reading strategies in the three phases of reading activity (pre, while, and post) and instructional media in the form of pictures and video. The strategies included the activation of students' background knowledge using picture and video. Those media also functioned as the model of text. However, the deployment of the use of strategies and media was not as what it supposed to be. It could not work well since the teacher did not understand the concept of scaffolding appropriately. 
In teaching reading, teachers should understand well the steps or procedures as scaffolding in reading comprehension. First, in the steps of pre-reading the teacher did not only do observation and questioning, they could take many sets of steps in teaching on condition that they could assist students comprehend text. The activity included (1) teaching students how to activate their background knowledge in connection with the topic to be read; (2) explicitly teaching key specialized vocabulary related to the topic; (3) teaching and having students practice how to set a purpose for reading; (3) using an anticipation-reaction guide to help students link new and prior knowledge and activate students' interest and curiosity for the topic, promoting motivation and engagement.

Second, in while-reading the teachers did experimentation and association activities which were also done not as what it supposed to be. The step actually can include activities such as (1) explicitly teaching students to ask and answer questions about text; (2) using graphic organizers which are visual representations that help students identify, organize, and remember important ideas from what they read; (3) explicitly teaching comprehension monitoring strategies, or fix-up strategies when comprehension breaks down such as re-reading, asking someone questions about the text, considering relevant background knowledge, and examining the graphics more carefully

Thirdly, in post-reading, the teacher did communication activities which were also done not as what it supposed to be. The step actually can include activities such as (1) teaching students how to use self-questioning strategies to reflect on what they have read; (2) explicitly teaching students to summarize the main ideas of what they read; and (3) explicitly teaching the use of graphic organizer.

The teachers are responsible for their students' success in their ZPD to become strategic readers. Becoming strategic is a developmental process; it occurs over time as students encounter increasingly difficult texts and new situations. The same relatively small set of strategies emerges quite early in students' development. Thus, reading strategy and media become the forms of scaffolding to be given as steps or assistance to help the students become autonomous learners.

\section{CONCLUSION}

Scaffolding can be applied in a variety of situation and in a variety of lesson formats. In ELT, it can be deployed in the teaching of reading to support and improve the students' performance before, during, and after reading activities. Such practices and experiences assist students to foster their essential skills for understanding and extracting meaning from text and boost their performance on reading comprehension assessment. In addition, students who benefit from the use of scaffolding are considered as independent readers and cold express ideas in a variety of ways. It is recommended that 
teachers understand the concept of scaffolding in socio-cognitive theory and deploy the types of scaffolding to enhance students’ reading competence.

\section{REFERENCES}

[1] Engel, L. C., \& Frizzell, M. O. (2015). Competitive comparison and PISA bragging rights: subnational uses of the OECD's PISA in Canada and the USA. Discourse: Studies in the Cultural Politics of Education, 36(5), 665-682.

[2] Kemendikbud. (2016). Laporan Hasil Ujian Nasional SMA/MA/SMK Tahun Pelajaran 2015/2016. Available at http://litbang.kemdikbud.go.id/index.php/statplanet-balitbang/ujian-nasional/hasil-ujiannasional-sma

[3] Jalivand, M. (2014). The effect of peer and teacher scaffolding on the reading comprehension of EFL learners in asymmetrical and symmetrical groups. Journal of Teaching Language Skills, 32(4), 1-17.

[4] Abdullah, M. R. T. L., Hussin, Z., \& Zakaria, A. R. (2013). Learning scaffolding model for undergraduate English language learning: bridging formal and informal learning. TOJET: The Turkish online journal of educational technology, 12(2).

[5] Vygotsky, L. (1978). Mind in society: The development of higher psychological processes. Cambridge. MA: Harvard University Press.

[6] Wilkinson, D., \& Birmingham, P. (2003). Using research instruments: A guide for researchers. Psychology Press.

[7] Duff, P. (2012). How to carry out case study research. Research methods in second language acquisition: A practical guide, 95-116.

[8] Garner, R., \& Scott, G. M. (2013). Doing qualitative research: designs, methods, and techniques. Pearson Education.

[9] Duffy, G.G. (2002). The case for direct explanation of strategies. In C. C. Block, \& M. Pressley (Eds.),

[10]Coiro, J., \& Dobler, E. (2007). Exploring the online reading comprehension strategies used by sixth-grade skilled readers to search for and locate information on the Internet. Reading research quarterly, 42(2), 214-257.

[11] Bannink, A. (2009). How to capture growth?-Video narratives as an instrument for assessment in teacher education. Teaching and teacher education, 25(2), 244-250.

[12] Crook, A., Mauchline, A., Maw, S., Lawson, C., Drinkwater, R., Lundqvist, K., \& Park, J. (2012). The use of video technology for providing feedback to students: Can it enhance the feedback experience for staff and students?. Computers \& Education, 58(1), 386-396. 